\title{
Primary solid lung cancerous nodules with different sizes: computed tomography features and their variations
}

\author{
Zhi-gang Chu ${ }^{1 \dagger}$, Yan Zhang ${ }^{1,2 \dagger}$, Wang-jia Li ${ }^{1}$, Qi Li ${ }^{1}$, Yi-neng Zheng ${ }^{1}$ and Fa-jin Lv ${ }^{1 *}$ (D)
}

\begin{abstract}
Background: The computed tomography (CT) features of small solid lung cancers and their changing regularity as they grow have not been well studied. The purpose of this study was to analyze the CT features of solid lung cancerous nodules (SLCNS) with different sizes and their variations.

Methods: Between February 2013 and April 2018, a consecutive cohort of 224 patients (225 nodules) with confirmed primary SLCNs was enrolled. The nodules were divided into four groups based on tumor diameter (A: diameter $\leq 1.0 \mathrm{~cm}$, 35 lesions; B: $1.0 \mathrm{~cm}<$ diameter $\leq 1.5 \mathrm{~cm}, 60$ lesions; C: $1.5 \mathrm{~cm}<$ diameter $\leq 2.0 \mathrm{~cm}, 63$ lesions; and D: $2.0 \mathrm{~cm}<$ diameter $\leq 3.0 \mathrm{~cm}, 67$ lesions). CT features of nodules within each group were summarized and compared.

Results: Most nodules in different groups were located in upper lobes (groups A-D:50.8\%-73.1\%) and had a gap from the pleura (groups A-D:89.6\%-100\%). The main CT features of smaller (diameter $\leq 1 \mathrm{~cm}$ ) and larger (diameter $>1 \mathrm{~cm}$ ) nodules were significantly different. As nodule diameter increased, more lesions showed a regular shape, homogeneous density, clear but coarse tumor-lung interface, lobulation, spiculation, spinous protuberance, vascular convergence, pleural retraction, bronchial truncation, and beam-shaped opacity $(p<0.05$ for all). The presence of halo sign in all groups was similar (17.5\%-22.5\%; $p>0.05)$.

Conclusions: The CT features vary among SLCNs with different sizes. Understanding their changing regularity is helpful for identifying smaller suspicious malignant nodules and early determining their nature in follow-up.
\end{abstract}

Keywords: Solid pulmonary nodule, Lung cancer, Computed tomography

\section{Background}

Lung cancer is the most common type of tumor and the leading cause of cancer-related mortality worldwide $[1,2]$. Pulmonary nodules are one of the main presentations of lung cancer; therefore, they have always been the key point of research. Based on their density features on computed tomography (CT) images, cancerous nodules can be generally divided into solid and subsolid nodules, each with significantly different morphological and pathological features [3]. Several studies have been conducted on the differential diagnosis of benign and malignant subsolid nodules [4-8] and the solid ones [9-13]. Compared with subsolid lung cancerous nodules, the solid ones have a

\footnotetext{
* Correspondence: cyscitg@163.com

†Zhi-gang Chu and Yan Zhang contributed equally to this work.

'Department of Radiology, The First Affiliated Hospital of Chongqing Medical University, 1\# Youyi Road, Yuanjiagang, Yuzhong district, Chongqing, China Full list of author information is available at the end of the article
}

worse prognosis because of their rapid growth [14-16] and earlier metastases [16-19]. Therefore, early identification of malignant solid nodules, particularly the smaller ones, based on CT features, is of great value for their prognosis.

Among the various CT features, spiculation, lobulation, vascular convergence, and pleural retraction have been associated with malignancy in lung cancer [6, 20-25]; therefore, they are helpful in differentiating benign from malignant nodules. However, these features are usually absent in smaller nodules, making their diagnosis challenging. Management of smaller nodules has mainly relied on clinical follow-up, using changes in nodule size to determine benignity or malignancy [26-28]. However, there is no systematic report on changes other than those in size, including shape, density, margins, interface, and internal characteristics; furthermore, the clinical significance of 
these changes remains unclear. Therefore, further investigating $\mathrm{CT}$ features associated with the changing regularity of solid lung cancerous nodules (SLCNs) with different sizes has the potential to greatly improve early detection of malignant nodules.

To date, no study has reported imaging features associated with the development of primary SLCNs. Therefore, the purpose of this study was to investigate and summarize CT manifestations of primary SLCNs and their differences based on the nodules size and to provide a reference for early and accurate identification of potentially malignant small nodules.

\section{Methods}

\section{Patients}

The present study enrolled patients with pathologically confirmed peripheral lung cancer between February 2013 and April 2018. All patients underwent chest CT examination before surgery. Inclusion criteria were met by patients with (1) lesions comprising nodules with diameter $\leq 3 \mathrm{~cm}$; (2) an interval of 1 month between chest CT scan and surgery, and (3) lesions not treated with antitumor therapy before CT examination. Patients were excluded if their CT images were of poor quality (5 cases) or if the lesions were metastatic lung cancers (14 cases). A total of 224 patients (225 lesions) were included in the study.

\section{CT examinations}

All patients were examined using a 64-slice spiral CT scanner (SOMATOM Definition Flash, Siemens, Germany) with the following settings: tube voltage, $140 \mathrm{kVp}$; tube current calculated according to individuals' weight, height, and body mass index; rotation time, $0.5 \mathrm{~s}$; pitch, 1.0 ; collimation, $0.6 \mathrm{~mm}$; slice thickness and interval for axial images, $5 \mathrm{~mm}$ and $5 \mathrm{~mm}$, respectively; and reorganization interval, $1 \mathrm{~mm}$. Upon CT examination, patients were put in the supine position with both hands near the head. Image acquisition was performed from the level of the thoracic inlet to inferior to the costophrenic angle. Images were obtained with mediastinal window (width, $400 \mathrm{HU}$; level, $30 \mathrm{HU}$ ) and lung window (width, $1500 \mathrm{HU}$; level, -600 $\mathrm{HU})$ settings.

\section{Image analysis}

All patients' CT data were reviewed on a workstation (Advantage Workstation 4.6; GE Healthcare) by two senior chest radiologists who were blinded to the pathological results of lesions. Interpretation discrepancy, if any, was resolved by consensus.

The followings features of the lesions were evaluated on CT images: size (average of the maximal long-axis and perpendicular maximal short-axis dimension); distribution in different lobes (left superior and inferior lobes and right superior, middle, and inferior lobes); location (clinging to the pleura or not); shape (regular: oval, round, and polygonal or irregular); internal features (calcification, air bronchogram, vacuole sign, or cavity); density (homogenous or heterogeneous); margins (lobulation, spiculation, spinous protuberance); and tumorlung interface (coarse, unclear, or smooth). In addition, peripheral lesion areas were also evaluated, including vascular convergence, pleural retraction, bronchial truncation, and beam-shaped opacity. Pleural effusions and lymph nodes in the hilum and mediastinum were further evaluated. Enlarged mediastinal and hilar lymph nodes were generally defined as those with diameter $>1 \mathrm{~cm}$ in short axis on chest CT scans.

For investigating the differences in $\mathrm{CT}$ features of SLCNs with different sizes, especially for the smaller ones, nodules were divided into four groups based on tumor size: Group A: diameter $\leq 1.0 \mathrm{~cm}$; Group B: $1.0 \mathrm{~cm}<$ diameter $\leq 1.5 \mathrm{~cm}$; Group C: $1.5 \mathrm{~cm}<$ diameter $\leq$ $2.0 \mathrm{~cm}$; and Group D: $2.0 \mathrm{~cm}<$ diameter $\leq 3.0 \mathrm{~cm}$.

\section{Statistical analysis}

Clinical data and CT features of nodules were statistically analyzed for each group. Continuous variables were expressed as mean \pm standard deviation, whereas categorical variables were expressed as absolute number and percentage. Independent sample $t$-tests were used to compare age among different groups. Chi-square test was used to compare the differences in patients' clinical and pathological data, distribution and location of nodules, and various CT features among the groups. TukeyKramer test was used for multiple comparisons among the groups. A $p$-value less than 0.05 was considered statistically significant. All statistical analyses were performed using the statistical software SPSS (version 22.0 for Windows, SPSS Inc., Chicago, Illinois, USA).

\section{Results}

\section{Patient characteristics}

Among the 224 patients, 129 (57.6\%) were male and 95 (42.4\%) were female. Patients were aged $38-83$ years, with an average age of $61.7 \pm 9.5$ years. A total of 127 (56.7\%) cases had cough, expectoration, hemoptysis, chest pain, or chest tightness. The number of SLCNs in groups $\mathrm{A}, \mathrm{B}, \mathrm{C}$, and $\mathrm{D}$ was $35,60,63$, and 67 , respectively. Table 1 summarizes the clinical and pathological data of patients included in each group. No significant differences were found in gender, age, clinical symptoms, smoking history, and histopathological types of lung cancer among the four groups $(p>0.05)$.

\section{Lesion distribution and location}

Nodule distribution and location are summarized in Table 2. In all four groups, nodules were mainly 
Table 1 Patients' clinical and pathological data

\begin{tabular}{|c|c|c|c|c|c|}
\hline & $\begin{array}{l}\text { Group A } \\
(n=35)\end{array}$ & $\begin{array}{l}\text { Group B } \\
(n=60)\end{array}$ & $\begin{array}{l}\text { Group C } \\
(n=63)\end{array}$ & $\begin{array}{l}\text { Group D } \\
(n=67)\end{array}$ & $p$-value \\
\hline Age (years) & $59.3 \pm 9.2$ & $63.0 \pm 10.6$ & $60.9 \pm 8.3$ & $64.0 \pm 9.0$ & 0.841 \\
\hline Male & $18(51.4)$ & $35(58.3)$ & $36(57.1)$ & $41(61.2)$ & 0.821 \\
\hline Smokers & $12(34.3)$ & $20(33.3)$ & $29(46.0)$ & $34(50.8)$ & 0.157 \\
\hline Clinical symptoms & $16(45.7)$ & $32(53.3)$ & $42(66.7)$ & $37(55.2)$ & 0.204 \\
\hline \multicolumn{6}{|l|}{ Pathological types } \\
\hline Adenocarcinoma & $32(91.4)$ & $55(91.7)$ & $51(81.0)$ & $56(83.6)$ & 0.245 \\
\hline Squamous cell carcinoma & $1(2.9)$ & $5(14.3)$ & $10(15.9)$ & $6(9.0)$ & 0.191 \\
\hline Others & $2(5.7)$ & $0(0)$ & $2(3.2)$ & $5(7.5)$ & 0.174 \\
\hline
\end{tabular}

The data are expressed as $n$ (\%)

distributed in the upper lobes (50.8-73.1\%) and most of them did not cling to the pleura (89.6-100\%).

\section{CT characteristics of lesions and their surroundings}

Nodule CT features are summarized in Table 3. As nodule diameter increased, more lesions showed a regular shape, homogeneous density, clear but coarse tumorlung interface, lobulation, spiculation, spinous protuberance, vascular convergence, pleural retraction, bronchial truncation, and beam-shaped opacity ( $p<0.05$ for all) (Figs. 1, 2, 3 and 4). However, the significant differences in various $\mathrm{CT}$ features were mainly detected between nodules in group A (diameter $\leq 1 \mathrm{~cm}$ ) and those in groups $\mathrm{B}, \mathrm{C}$ and $\mathrm{D}$ (diameter $>1 \mathrm{~cm}$ ). Additionally, the presence of halo sign in groups A and B was slightly higher than that in groups $C$ and $D$, although not significantly different $(p>0.05)$. There was also no significant difference in the incidence of calcification, vacuole, and cavity among the four groups.

\section{CT characteristics of suspicious malignant nodules in group a}

Along with lesion distribution, location, and morphological features, the main CT characteristics indicating suspicious malignant nodules in group A are summarized in Table 4.

\section{Lymph nodes in the hilum and mediastinum and pleural effusion}

As nodule size increased, the incidence of enlarged lymph nodes in the hilum or mediastinum also gradually increased $(8.6,18.3,27.0$, and $46.3 \%$ for groups $\mathrm{A}, \mathrm{B}, \mathrm{C}$, and $\mathrm{D}$, respectively; $p<0.001$ ). The incidence of pleural effusion was extremely low in all four groups.

\section{Discussion}

This study showed a similar distribution of SLCNs in the different groups categorized based on nodule size. Lung cancers are generally believed to be mainly distributed in

Table 2 Distribution and location of nodules

\begin{tabular}{|c|c|c|c|c|c|}
\hline & $\begin{array}{l}\text { Group A } \\
(n=35)\end{array}$ & $\begin{array}{l}\text { Group B } \\
(n=60)\end{array}$ & $\begin{array}{l}\text { Group C } \\
(n=63)\end{array}$ & $\begin{array}{l}\text { Group D } \\
(n=67)\end{array}$ & $p$-value \\
\hline Right lung & $28(80.0)$ & $33(55.0)$ & $31(49.2)$ & $42(62.7)$ & 0.022 \\
\hline $\mathrm{SL}$ & $15(42.9)$ & $20(33.3)$ & $16(25.4)$ & $29(43.3)$ & 0.137 \\
\hline$M L$ & $5(14.3)$ & $2(3.3)$ & $4(6.4)$ & $5(7.5)$ & 0.252 \\
\hline $\mathrm{IL}$ & $8(22.9)$ & $11(18.3)$ & $11(17.5)$ & $8(11.9)$ & 0.540 \\
\hline Left lung & $7(20)$ & $27(45)$ & $32(50.8)$ & $25(37.4)$ & 0.022 \\
\hline $\mathrm{SL}$ & $6(17.1)$ & $17(28.3)$ & $16(25.4)$ & $20(29.9)$ & 0.550 \\
\hline $\mathrm{IL}$ & $1(2.9)$ & $10(16.7)$ & $16(25.4)$ & $5(7.5)$ & 0.005 \\
\hline SLs of both lungs & $21(60.0)$ & $37(61.7)$ & $32(50.8)$ & $49(73.1)$ & 0.074 \\
\hline ILs of both lungs & $9(25.8)$ & $21(35)$ & $27(42.9)$ & $13(19.4)$ & 0.026 \\
\hline \multicolumn{6}{|l|}{ Relationship with pleura } \\
\hline Not clinging to pleura & $35(100.0)$ & $58(96.7)$ & $58(92.1)$ & $60(90)$ & 0.114 \\
\hline Clinging to pleura & $0(-)$ & $2(3.33)$ & $3(4.76)$ & $6(8.96)$ & 0.114 \\
\hline
\end{tabular}

$S L$ Superior lobe, ML Middle lobe, IL Inferior lobe

The data are expressed as $\mathrm{n}(\%)$ 
Table 3 CT features of nodules in different size

\begin{tabular}{|c|c|c|c|c|c|c|}
\hline CT features & $\begin{array}{l}\text { Group A } \\
(n=35)\end{array}$ & $\begin{array}{l}\text { Group B } \\
(n=60)\end{array}$ & $\begin{array}{l}\text { Group C } \\
(n=63)\end{array}$ & $\begin{array}{l}\text { Group D } \\
(n=67)\end{array}$ & $p$-value & Sig. \\
\hline \multicolumn{7}{|l|}{ Shape } \\
\hline Round & $9(25.7)$ & $14(23.3)$ & $15(23.8)$ & $15(22.4)$ & 0.986 & - \\
\hline Oval & $16(45.7)$ & $41(68.3)$ & $42(66.7)$ & $48(71.6)$ & 0.060 & - \\
\hline Polyonal & $5(14.3)$ & $3(5)$ & $4(6.3)$ & $2(3.0)$ & 0.154 & - \\
\hline Irregular & $5(14.3)$ & $2(3.3)$ & $2(3.2)$ & $2(3.0)$ & 0.049 & $\mathrm{~A} / \mathrm{BCD}$ \\
\hline Size $(m m)$ & $8.2 \pm 1.4$ & $12.8 \pm 1.3$ & $17.7 \pm 1.4$ & $24.1 \pm 2.7$ & / & \\
\hline Heterogeneous density & $18(51.4)$ & $15(25)$ & $8(12.7)$ & $3(4.5)$ & 0.000 & $A / B C D$ \\
\hline \multicolumn{7}{|l|}{ Internal feature } \\
\hline Calcification & $0(-)$ & $0(-)$ & $1(1.6)$ & $1(1.5)$ & 0.687 & - \\
\hline Vacuole & $5(14.3)$ & $5(14.3)$ & $4(6.4)$ & $11(16.4)$ & 0.242 & - \\
\hline Air bronchogram & $1(2.9)$ & $1(1.7)$ & $5(7.9)$ & $12(17.9)$ & 0.005 & $A / B C D$ \\
\hline Cavity & 0 & $1(1.7)$ & $7(11.1)$ & $4(6.0)$ & 0.051 & - \\
\hline \multicolumn{7}{|l|}{ Margin } \\
\hline Lobulation & $10(28.6)$ & $22(36.7)$ & $36(57.1)$ & $47(70.1)$ & 0.000 & $\mathrm{AB} / \mathrm{CD}$ \\
\hline Spiculation or spinous protuberance & $7(20)$ & $27(45)$ & $36(57.1)$ & $47(70.1)$ & 0.000 & $\mathrm{~A} / \mathrm{BCD}$ \\
\hline Halo sign & $7(20)$ & $15(25)$ & $11(17.5)$ & $12(17.9)$ & 0.712 & - \\
\hline \multicolumn{7}{|l|}{ Tumor-lung interface } \\
\hline Coarse & $26(74.3)$ & $48(80)$ & $55(87.3)$ & $64(95.5)$ & 0.013 & $A / D$ \\
\hline Unclear & $6(17.1)$ & $7(11.7)$ & $3(4.8)$ & $1(1.5)$ & 0.016 & $\mathrm{~A} / \mathrm{D}$ \\
\hline Smooth & $3(8.6)$ & $5(14.3)$ & $5(7.9)$ & $2(3.0)$ & 0.553 & - \\
\hline Bronchial truncation & $0(-)$ & $8(13.3)$ & $10(15.9)$ & $18(26.9)$ & 0.005 & $\mathrm{~A} / \mathrm{BCD}$ \\
\hline Vascular convergence & $6(17.1)$ & $32(53.3)$ & $43(68.3)$ & $50(74.6)$ & 0.000 & $A / B C D$ \\
\hline Beam-shaped opacity & $3(8.6)$ & $15(25)$ & $15(23.8)$ & $26(38.8)$ & 0.010 & $\mathrm{~A} / \mathrm{BCD}$ \\
\hline Pleural retraction & $3(8.6)$ & $22(36.7)$ & $28(44.4)$ & $34(50.8)$ & 0.000 & $A / B C D$ \\
\hline Obstructive pneumonia & $0(-)$ & $1(1.67)$ & $4(6.4)$ & $5(7.5)$ & / & / \\
\hline
\end{tabular}

The data are expressed as $n$ (\%). Heterogeneous density indicates the density of nodules in addition to calcification, vacuole, air bronchogram, and cavity. $A / B C D$ indicates there is significant difference between group $A$ and $B$ but no significant difference among groups of $B, C$ and $D$. $A B / C D$ indicates there is significant difference between group $B$ and $C$ but no significant difference between group $A$ and $B$ or group $C$ and $D$. A/D indicates there is significant difference only between group $A$ and $D$

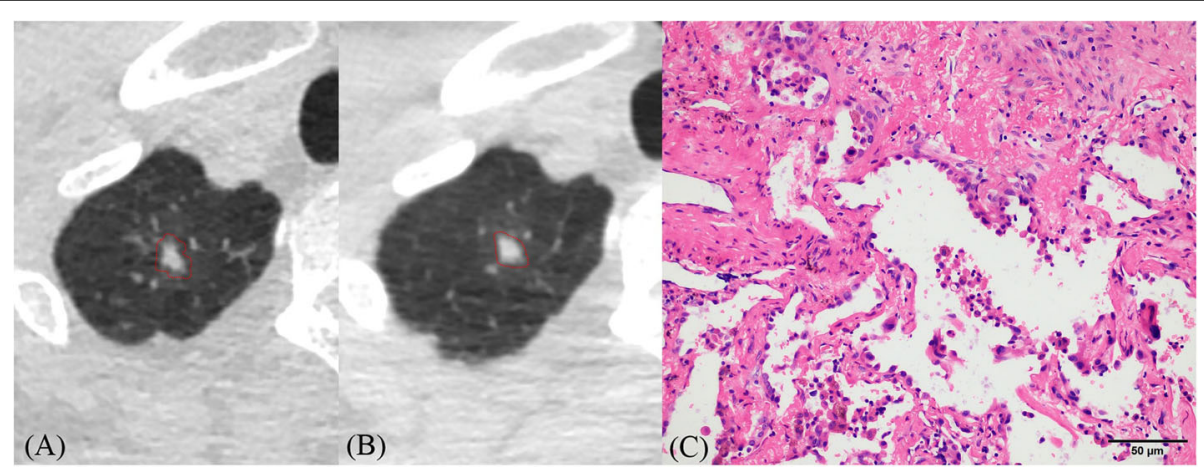

Fig. 1 a-c CT images of lung adenocarcinoma. a CT image shows an irregular solid nodule $(6 \times 4 \mathrm{~mm})$ with blurred margin located in the apical segment of the right upper lobe. $\mathbf{b}$ One year later, the size of this nodule increased $(8 \times 6 \mathrm{~mm})$ and its shape and margin became more regular (triangle) and clearer than before. $\mathbf{c}$ Histopathologic analysis of the resected nodule revealed microinvasive adenocarcinoma 


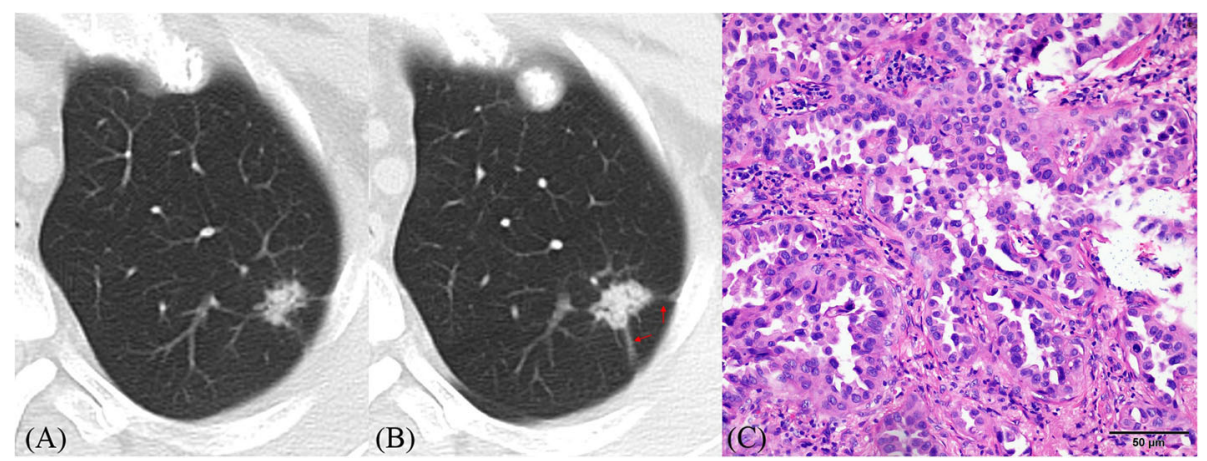

Fig. 2 a-c CT images of lung adenocarcinoma. a CT image shows an irregular solid nodule $(10 \times 15 \mathrm{~mm})$ with heterogeneous density located in the apico-posterior segment of the left upper lobe. $\mathbf{b}$ One year later, its size $(14 \times 16 \mathrm{~mm})$ and density increased; the tumor-lung interface was clearer and spiculation (red arrows) was more obvious than before. $\mathbf{c}$ Histopathologic analysis of the resected nodule revealed invasive adenocarcinoma

the upper lobes [29-31]. Regarding nodule location, most nodules, particularly the smaller ones, were not found to be connected with the adjacent pleura. It appeared that the space between the tumor and pleura subsists until the nodules grow large enough to occupy it [32]. It is possible that a SLCN is typically derived from the distal bronchus, and a gap exists between the lesion and the pleura. These findings show that smaller nodules clinging to the pleura, which are usually detected on chest CT scan, are less likely to be lung cancer.

In this study, the CT features of smaller lesions $(\leq 1$ $\mathrm{cm}$ ) were usually different from those of the bigger ones $(>1 \mathrm{~cm})$. As nodule size increased, the lesions acquired a more regular shape and the margins and surrounding features also gradually increased. It may be because a nodule becomes more regular with an increase in size, and the limitation of the surrounding structure becomes more obvious. Lobulation, spiculation, pleural retraction, and vascular convergence are considered common signs of malignancy in lung cancer [6,20-25]. However, for smaller nodules, traction and invasion of surrounding blood vessels and tissues, as well as tumor and peritumoral fibrosis were not obvious. As nodules size increased, the invasion of the surrounding tissue also increased, and more surrounding signs were evident.

Siegelman et al. [33] reported that the incidence of coarse tumor-lung interface was significantly higher in lung cancers than in benign lesions. In this study, tumor-lung interface in each group was mainly coarse. Additionally, the incidence of coarse interface increased with the increasing size of the nodule. This may be because tumor cells locally infiltrate the peripheral tissue,

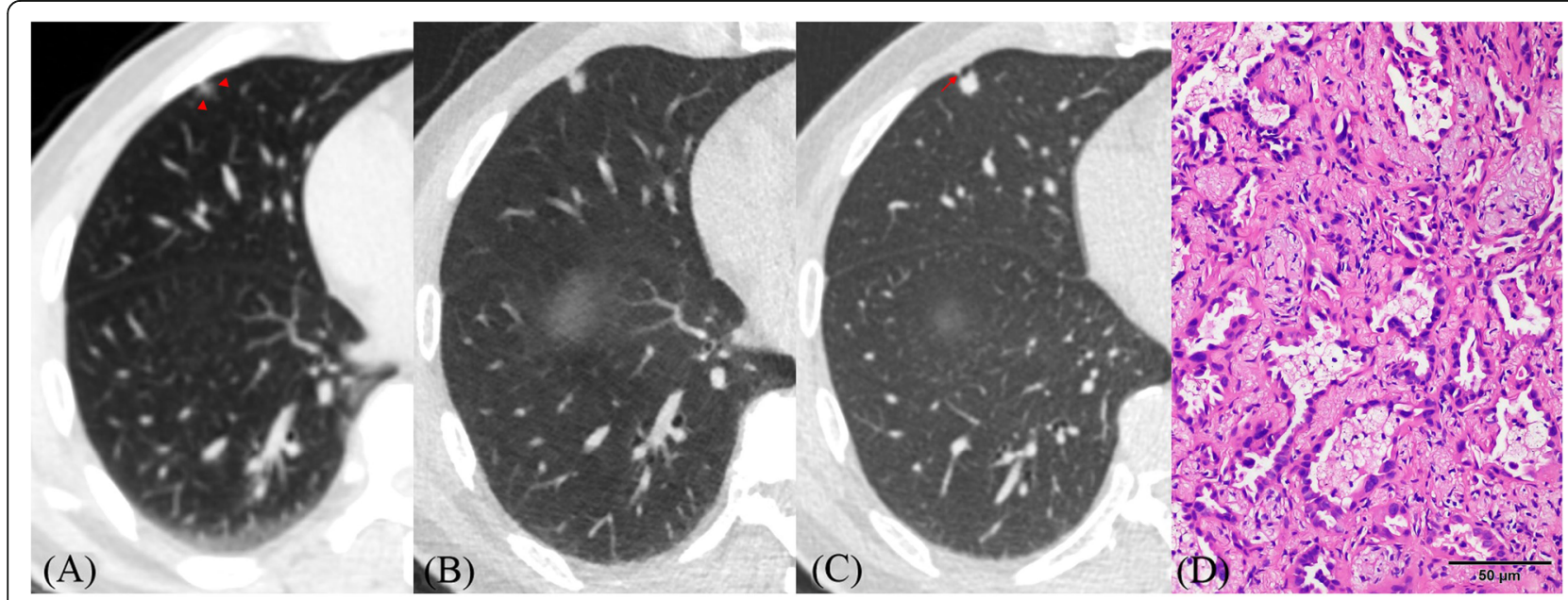

Fig. 3 a-d CT images of lung adenocarcinoma. a CT image shows a nodule $(7.0 \times 5.0 \mathrm{~mm})$ with heterogeneous density and blurred tumor-lung interface (red arrowheads) located in the subpleural zone of the right middle lobe. $\mathbf{b}$ One year and a half later, it grew a little (8.0 $\times 6.0 \mathrm{~mm}$ ) but its density significantly increased. c Two years and a half later, its size $(8.0 \times 8.0 \mathrm{~mm})$ slightly increased but margins became clearer than before. Lobulation and pleural indentation (red arrow) are obvious. $\mathbf{d}$ Histopathologic analysis of the resected nodule revealed adenocarcinoma without significant invasion 


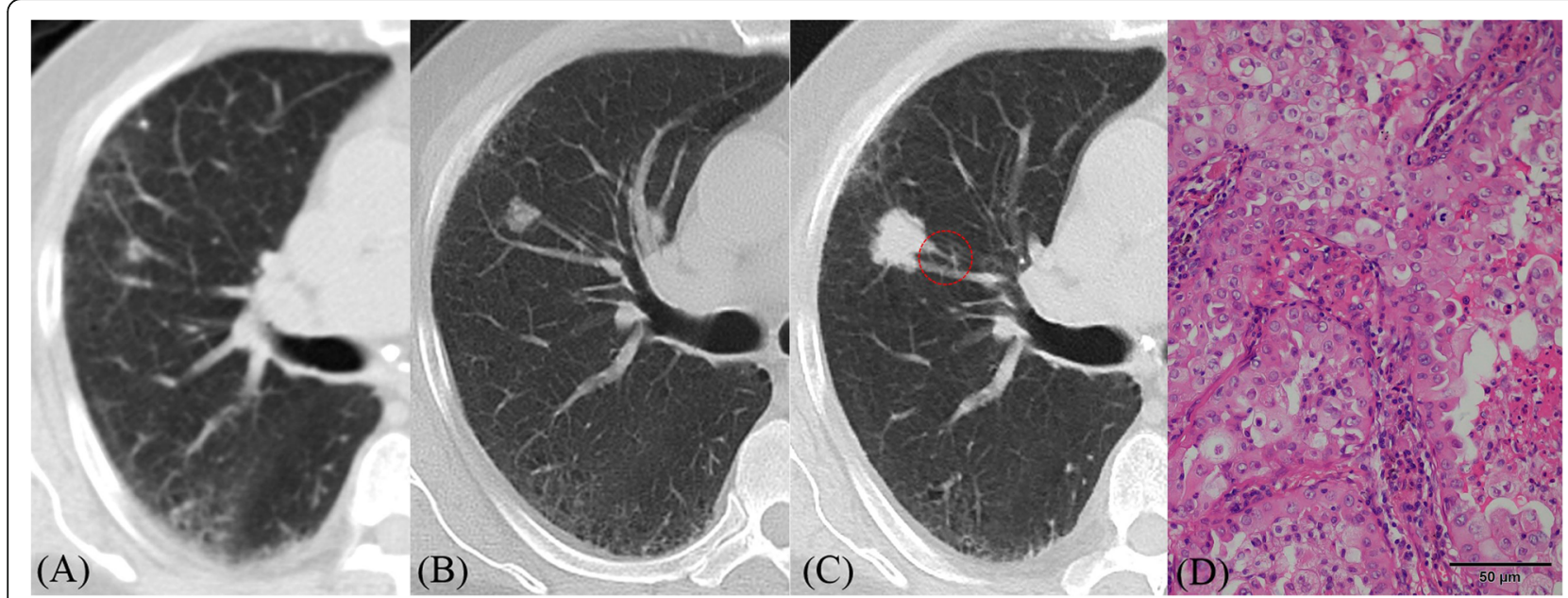

Fig. 4 a-d CT images of lung adenocarcinoma. a CT image shows a small nodule $(5 \mathrm{~mm}$ ) beside a blood vessel in the right upper lobe. $\mathbf{b}$ Eight months later, its size increased $(10 \times 11 \mathrm{~mm})$ but its density was heterogeneous. c Fifteen months later, its size significantly increased $(18 \times 19$ $\mathrm{mm})$; furthermore, its density increased, and it became more homogeneous. Additionally, lobulation sign and peripheral vascular convergence (red circle) were positive. $\mathbf{d}$ Histopathologic analysis of the resected nodule revealed invasive adenocarcinoma

particularly the bigger nodules. However, the smaller the nodules, the higher the incidence of unclear interface, which may be related to the relatively sparse tumor cells in the peripheral areas of those nodules. Therefore, for smaller solid nodules with unclear interface, the possibility of lung cancer cannot be completely excluded and follow-up is recommended in such cases to avoid an erroneous diagnosis.

The growth of solid lung cancer is a gradual process. The tumor cells gradually accumulate, and the lesion size continuously increases. Theoretically, tumor density is more homogeneous on plain CT scan with an increase in the lesion size. In the present study, small nodules, particularly those with diameter $<1 \mathrm{~cm}$, had a higher incidence of heterogeneous density. However, the incidence of

Table $4 \mathrm{CT}$ features indicating suspicious malignancy for group A nodules

\begin{tabular}{lll}
\hline CT features & Numbers & Percentage (\%) \\
\hline SLs of both lungs $^{\mathrm{a}}$ & 21 & 60.0 \\
Not clinging to pleura $^{\mathrm{a}}$ & 35 & 100.0 \\
Irregular shape $^{\mathrm{b}}$ & 5 & 14.3 \\
Heterogeneous density $^{\mathrm{b}}$ & 18 & 51.4 \\
Lobulation $^{\mathrm{c}}$ & 10 & 28.6 \\
Spiculation or spinous protuberance $^{c}$ & 7 & 20 \\
Coarse tumor-lung interface $^{\mathrm{a}}$ & 26 & 74.3 \\
Unclear tumor-lung interface $^{\mathrm{b}}$ & 6 & 17.1 \\
Halo sign $^{\mathrm{a}}$ & 7 & 20 \\
\hline SL Suprio lobe $^{\mathrm{a}}$ indicas
\end{tabular}

$S L$ Superior lobe, ${ }^{a}$ indicates the common features for group A-D nodules; ${ }^{\text {b }}$ indicates these features are relatively common in group $A$ nodules. ${ }^{C}$ indicates these features are relatively rare in group A nodules internal calcification, vacuole sign, or cavity was low in each group, as previously reported [34, 35]. Therefore, small solid nodules with heterogeneous density can be selectively observed, and lung cancer should be highly suspected once their density increases and becomes homogeneous.

Beam-shaped opacity is banded ground glass opacity, which is located on the side of the tumor close to the pleura in different directions. It is common in adenocarcinoma and highly significant in the diagnosis of lung cancer [36]. This sign may be related to the traction of the surrounding lung tissue. In this study, the incidence of beam-shaped opacity was higher in the group $\mathrm{D}$, but it was significantly lower in the group A. This implicates that small nodules do not cause significant changes in surrounding structures.

Halo sign is a nonspecific sign around solid pulmonary nodules, and its border is usually clear in lung cancer lesions [37]. In this study, a well-defined halo sign was mainly located on one side of the nodule, and its incidence was slightly higher in smaller lesions. Therefore, small solid nodules not presenting with other features but well-defined halo sign should be suspected for lung cancer.

Overall, regarding the small pulmonary nodules, follow-up seems to be an effective way to discriminate their nature based on changes in CT features. A recent study has confirmed that quantitative image features ("radiomics") can also help discriminate benign from malignant pulmonary nodules [38]. Additionally, quantitative radiomic signatures have shown the potential to reveal and predict the tumor growth rate, and they can help identify the indolent from aggressive lung cancer [39]. Thus, radiomics may provide a new way for 
evaluating and managing indeterminate pulmonary nodules in the future.

This study had several limitations. The evaluation of changing regularity of CT features for SLCNs was performed by comparing grouped nodules with different sizes rather than following only one group of lesions. Thus, results obtained here should be confirmed in clinical practice. Additionally, the pathological types of SLCNs varied but showed no significant differences among different groups. Therefore, present results seem to represent a general, rather than a specific tumor type. It should be noted that some tumor types within smaller samples may not conform to the general morphological development.

\section{Conclusion}

Morphological changes in SLCNs exhibited some degree of regularity in their growth process. With diameter increasing, more nodules showed a regular shape, homogeneous density, clear but coarse tumor-lung interface, and margin or peripheral signs. Thus, larger nodules could be easily diagnosed due to the presence of more features. However, malignancy should be suspected for smaller nodules located in the upper lobe that are not clinging to the pleura and are showing irregular shape, heterogeneous density, unclear tumor-lung interface, or a well-defined halo sign. Understanding the changing regularity of SLCNs is helpful for identifying smaller suspicious malignant nodules and for early determination of their nature during follow-up.

\section{Abbreviations}

$C T$ : computed tomography; SLCN: solid lung cancerous nodule

\section{Acknowledgments}

Not applicable.

\section{Authors' contributions}

Z-GC and YZ contributed to the data analysis and manuscript writing. W-JL, QL and Y-NZ were involved in performing data collection. F-JL was responsible for the study coordination. All authors have read and approved the manuscript, and ensure that this is the case.

\section{Funding}

This study was supported by the National Natural Science Foundation of China (81601545) and Chongqing Health and Family Planning Commission Foundation (2016MSXM018) of China. The funding was used to conduct all data analyses and cover publication fees. The funding bodies did not have any influence on the design of the study, collection, analysis, interpretation of data or in writing the manuscript.

\section{Availability of data and materials}

Please contact author (Zhi-gang Chu) for data requests.

\section{Ethics approval and consent to participate}

The Research Ethics Committee of The First Affiliated Hospital of Chongqing Medical University (IRB No. 2019-062) approved this study. All the participants provided written informed consent.

Consent for publication

Not applicable.

\section{Competing interests}

The authors declare that they have no competing interests.

\section{Author details}

${ }^{1}$ Department of Radiology, The First Affiliated Hospital of Chongqing Medical University, 1\# Youyi Road, Yuanjiagang, Yuzhong district, Chongqing, China.

${ }^{2}$ Department of Radiology, Chongqing Three Gorges Medical College,

Chongqing, China.

Received: 31 May 2019 Accepted: 18 October 2019

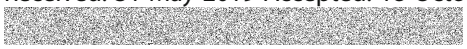

\section{References}

1. Chen W, Zheng R, Baade PD, Zhang S, Zeng H, Bray F, et al. Cancer statistics in China, 2015. CA Cancer J Clin. 2016;66:115-32.

2. Jemal A, Bray F, Center MM, Ferlay J, Ward E, Forman D. Global cancer statistics. CA Cancer J Clin. 2011;61:69-90.

3. Naidich DP, Bankier AA, MacMahon H, Schaefer-Prokop CM, Pistolesi M, Goo $J M$, et al. Recommendations for the management of subsolid pulmonary nodules detected at CT: a statement from the Fleischner society. Radiology. 2013;266:304-17.

4. Qiu ZX, Cheng Y, Liu D, Wang WY, Wu X, Wu WL, et al. Clinical, pathological, and radiological characteristics of solitary ground-glass opacity lung nodules on high-resolution computed tomography. Ther Clin Risk Manag. 2016;12:1445-53

5. Chung K, Jacobs C, Scholten ET, Goo JM, Prosch H, Sverzellati N, et al. LungRADS category 4X: does it improve prediction of malignancy in subsolid nodules? Radiology. 2017;284:264-71.

6. Hu H, Wang Q, Tang H, Xiong L, Lin Q. Multi-slice computed tomography characteristics of solitary pulmonary ground-glass nodules: differences between malignant and benign. Thorac Cancer. 2016;7:80-7.

7. Lee HY, Choi YL, Lee KS, Han J, Zo Jl, Shim YM, et al. Pure ground-glass opacity neoplastic lung nodules: histopathology, imaging, and management. AJR Am J Roentgenol. 2014;202:224-33.

8. Wu F, Tian SP, Jin $X$, Jing $R$, Yang $Y Q$, Jin $M$, et al. $C T$ and histopathologic characteristics of lung adenocarcinoma with pure ground-glass nodules 10 mm or less in diameter. Eur Radiol. 2017:27:1-7.

9. Walter JE, Heuvelmans MA, Bock GH, Yousaf-Khan U, Groen HJM, Aalst CMV, et al. Characteristics of new solid nodules detected in incidence screening rounds of low-dose CT lung cancer screening: the NELSON study. Thorax. 2018;73:741-7.

10. Walter JE, Heuvelmans MA, de Jong PA, Vliegenthart R, van Ooijen PMA, Peters RB, et al. Occurrence and lung cancer probability of new solid nodules at incidence screening with low-dose $C \mathrm{C}$ : analysis of data from the randomised, controlled NELSON trial. Lancet Oncol. 2016;17:907-16.

11. Shinohara S, Hanagiri T, Takenaka M, Chikaishi Y, Oka S, Shimokawa H, et al. Evaluation of undiagnosed solitary lung nodules according to the probability of malignancy in the American College of Chest Physicians (ACCP) evidencebased clinical practice guidelines. Radiol Oncol. 2014;48:50-5.

12. Sim YT, Poon FW. Imaging of solitary pulmonary nodule-a clinical review. Quant Imaging Med Surg. 2013;3:316-26.

13. Henschke Cl, Yankelevitz DF, Reeves AP, Cham MD. Image analysis of small pulmonary nodules identified by computed tomography. Mt Sinai J Med. 2011;78:882-93.

14. Oda S, Awai K, Murao K, Ozawa A, Utsunomiya D, Yanaga Y, et al. Volumedoubling time of pulmonary nodules with ground glass opacity at multidetector $\mathrm{CT}$ : assessment with computer aided three-dimensional volumetry. Acad Radiol. 2011;18:63-9.

15. Wang X, Han R, Guo F, Li X, Zheng W, Wang Q, et al. Analysis of growth curve type in pulmonary nodules with different characteristics. Zhongguo Fei Ai Za Zhi. 2017;20:334-40.

16. Hasegawa M, Sone S, Takashima S, Li F, Yang ZG, Maruyama Y, et al. Growth rate of small lung cancers detected on mass $C T$ screening. $\mathrm{Br} J$ Radiol. 2000;73:1252-9

17. Zhong W, Yang X, Bai J, Yang J, Manegold C, Wu Y. Complete mediastinal lymphadenectomy: the core component of the multidisciplinary therapy in resectable non-small cell lung cancer. Eur J Cardiothorac Surg. 2008; 34:187-95.

18. Wolf AS, Richards WG, Jaklitsch MT, Gill R, Chirieac LR, Colson $Y L$, et al. Lobectomy versus sublobar resection for small $(2 \mathrm{~cm}$ or less) non-small cell lung cancers. Ann Thorac Surg. 2011;92:1819-23. 
19. Lee SM, Park CM, Paeng JC, Im HJ, Goo JM, Lee HJ, et al. Accuracy and predictive features of FDG-PET/CT and CT for diagnosis of lymph node metastasis of $\mathrm{T} 1$ non-small-cell lung cancer manifesting as a subsolid nodule. Eur Radiol. 2012:22:1556-63.

20. Snoeckx A, Reyntiens P, Desbuquoit D, Spinhoven MJ, Van Schil PE, van Meerbeeck JP, et al. Evaluation of the solitary pulmonary nodule: size matters, but do not ignore the power of morphology. Insights Imaging. 2018:9:73-86.

21. Ost DE, Gould MK. Decision making in patients with pulmonary nodules. Am J Respir Crit Care Med. 2012;185:363-72.

22. Wang X, Lv L, Zheng Q, Huang X, Li B. Differential diagnostic value of 64 slice spiral computed tomographvy in solitary pulmonary nodule. Exp Ther Med. 2018;15:4703-8.

23. Harders SW, Madsen HH, Rasmussen TR, Hager H, Rasmussen F. High resolution spiral $\mathrm{CT}$ for determining the malignant potential of solitary pulmonary nodules: refining and testing the test. Acta Radiol. 2011;52:401-9.

24. Miyamoto A, Kurosaki A, Fujii T, Kishi K, Homma S. HRCT features of surgically resected invasive mucinous adenocarcinoma associated with interstitial pneumonia. Respirology. 2017;22:735-43.

25. Oda S, Awai K, Liu D, Nakaura T, Yanaga Y, Nomori H, et al. Ground-glass opacities on thin-section helical CT: differentiation between Bronchioloalveolar carcinoma and atypical adenomatous hyperplasia. AJR Am J Roentgenol. 2012;190:1363-8.

26. Gould MK, Donington J, Lynch WR, Mazzone PJ, Midthun DE, Naidich DP, et al. Evaluation of individuals with pulmonary nodules: when is it lung cancer? Diagnosis and management of lung cancer, 3rd ed: American College of Chest Physicians evidence-based clinical practice guidelines. Chest. 2013;143:e93S-120S

27. Patel VK, Naik SK, Naidich DP, Travis WD, Weingarten JA, Lazzaro R, et al. A practical algorithmic approach to the diagnosis and management of solitary pulmonary nodules: part 1: radiologic characteristics and imaging modalities. Chest. 2013;143:825-39.

28. Pinsky PF, Gierada DS, Nath PH, Munden R. Lung cancer risk associated with new solid nodules in the national lung screening trial. AJR Am J Roentgenol. 2017;209:1-6.

29. Lindell RM, Hartman TE, Swensen SJ, Jett JR, Midthun DE, Tazelaar HD, et al Five-year lung cancer screening experience: $C T$ appearance, growth rate, location, and histologic features of 61 lung cancers. Radiology. 2007;242 555-62.

30. Swensen SJ, Silverstein MD, Ilstrup DM, Schleck CD, Edell ES. The probability of malignancy in solitary pulmonary nodules. Application to small radiologically indeterminate nodules. Arch Intern Med. 1997;157:849-55.

31. Perandini S, Soardi G, Motton M, Oliboni E, Zantedeschi L, Montemezzi S. Distribution of solid solitary pulmonary nodules within the lungs on computed tomography: a review of 208 consecutive lesions of biopsyproven nature. Pol J Radiol. 2016;81:146-51.

32. Ohno Y, Hatabu H, Takenaka D, Higashino T, Watanabe H, Ohbayashi C, et al. CT-guided transthoracic needle aspiration biopsy of small $(<$ or $=20$ mm) solitary pulmonary nodules. AJR Am J Roentgenol. 2003;180:1665-9.

33. Siegelman SS, Khouri NF, Leo FP, Fishman EK, Braverman RM, Zerhouni EA Solitary pulmonary nodules: CT assessment. Radiology. 1986;160:307-12.

34. Grewal RG, Austin JH. CT demonstration of calcification in carcinoma of the lung. J Comput Assist Tomogr. 1994;18:867-71.

35. Zwirewich CV, Vedal S, Miller RR, Müller NL. Solitary pulmonary nodule: high-resolution CT radiologic-pathologic correlation. Radiology. 1991;179: 469-76.

36. Chu ZG, Sheng B, Liu MQ, Lv FJ, Li Q, Ouyang Y. Differential Diagnosis of Solitary Pulmonary Inflammatory Lesions and Peripheral Lung Cancers with Contrast-enhanced Computed Tomography. Clinics. (Sao Paulo). 2016; 71: 555-561.

37. Nambu A, Araki T, Taguchi Y, Ozawa K, Miyata K, Miyazawa M, et al. Focal area of ground-glass opacity and ground-glass opacity predominance on thin-section CT: discrimination between neoplastic and non-neoplastic lesions. Clin Radiol. 2005:60:1006-17.
38. Balagurunathan Y, Schabath MB, Wang H, Liu Y, Gillies RJ. Quantitative imaging features improve discrimination of malignancy in pulmonary nodules. Sci Rep. 2019;9(1):8528.

39. Lu H, Mu W, Balagurunathan Y, Qi J, Abdalah MA, Garcia AL, et al. Multiwindow CT based Radiomic signatures in differentiating indolent versus aggressive lung cancers in the National Lung Screening Trial: a retrospective study. Cancer Imaging. 2019;19(1):45.

\section{Publisher's Note}

Springer Nature remains neutral with regard to jurisdictional claims in published maps and institutional affiliations.
Ready to submit your research? Choose BMC and benefit from:

- fast, convenient online submission

- thorough peer review by experienced researchers in your field

- rapid publication on acceptance

- support for research data, including large and complex data types

- gold Open Access which fosters wider collaboration and increased citations

- maximum visibility for your research: over $100 \mathrm{M}$ website views per year

At BMC, research is always in progress.

Learn more biomedcentral.com/submissions 